\title{
Recent achievements and perspectives for large-scale recombinant production of antimicrobial peptides
}

\author{
David Wibowo, ${ }^{1,2^{*}}$ Chun-Xia Zhao ${ }^{1 *}$
}

${ }^{1}$ Australian Institute for Bioengineering and Nanotechnology, The University of Queensland, St Lucia QLD 4072, Australia.

${ }^{2}$ Griffith Institute for Drug Discovery, Griffith University, Nathan QLD 4111, Australia.

\author{
*Correspondence \\ David Wibowo. Email: d.wibowo@griffith.edu.au. ORCID ID: 0000-0001-6919-3355 \\ Chun-Xia Zhao. Email: z.chunxia@uq.edu.au. ORCID ID: 0000-0002-3365-3759
}

\section{Keywords}

Antimicrobial peptides; fusion proteins; protein purification; recombinant production

\begin{abstract}
Antibiotic resistance poses a growing threat to global public health. It is urgent to develop new alternative antibiotics. Antimicrobial peptide (AMP) is a diverse class of natural occurring molecules that constitute immune systems of living organisms. More than 2,500 AMPs have been identified and isolated from natural sources. Compared to conventional antibiotics, AMPs exhibit antimicrobial activities against a broad spectrum of microorganisms including bacteria, fungi, and even viruses. More importantly, the unique antimicrobial mechanisms of AMPs make it difficult for microorganisms to develop resistance. Therefore, it is very promising to develop AMPs as high-value antimicrobial candidates. This MiniReview provides an update of recent progresses in recombinant production of AMPs after fusion of AMP with carrier proteins and their scale-up. Key factors including selection of expression host and fusion tags are firstly introduced, followed by subsequent discussions on purification of fusion proteins and recovery of antimicrobial peptides. The scale production of AMPs is also explored.
\end{abstract}




\section{Introduction}

Advances in genome sequencing and transcriptomics have enabled the identification and development of a large antimicrobial peptide (AMP) library (Rezaei Javan et al. 2018). AMPs typically composed of 5-100 amino acids are ubiquitous in nature and present in both prokaryotic and eukaryotic organisms as multipotent components constituting their innate immune defense systems (Ganz 2003; Zasloff 2002). AMPs have evolutionarily appeared as an effective weapon against potentially harmful microbes, including viruses, bacteria and fungi. This is achieved by means of disrupting cell membranes and/or inhibiting intracellular activities (reviewed in (Nguyen et al. 2011; Travkova et al. 2017)). The multiple site-targeting ability coupled with quick killing have made it difficult for the affected microorganisms to develop resistance against AMPs, which is one of the key characteristics that conventional antibiotics lack, thus resulting in the rapid emergence of antibiotic-resistant infections (Ventola 2015). In this regards, AMPs are expectedly viewed as an alternative to antibiotics (Mishra et al. 2017). Other advantages of using AMPs include relatively easy chemical modification (Bahar and Ren 2013) and surface immobilization (Onaizi and Leong 2011) facilitated by the rich chemistry of diverse amino acids. It further improves the activities of AMPs and broadens their applications in other fields, including wound healing (Mangoni et al. 2016), root canal treatment and regenerative endodontics (Mai et al. 2017), coating of biomedical devices (Casciaro et al. 2018; Dutta et al. 2018; Onaizi and Leong 2011) and anticancer therapeutics (Gaspar et al. 2013; Nordström and Malmsten 2017). Certainly, the development of AMPs is an area of intense and expanding research.

To date, over 2,500 AMPs has been identified and registered in the Antimicrobial Peptide Database (Wang et al. 2016). These AMPs are classified based on their sources (bacteria, plants, animal or synthetic), functions (antibacterial, antiviral, antifungal), secondary structures ( $\alpha$-helix, $\beta$-sheet, extended, cyclic), and their molecular targets (cell surface, DNA and protein synthesis). Despite the progress in the development of AMPs, their large-scale production and their utilities in clinical trials remain challenging (Eckert 2011). One of the challenges is the cost to produce AMPs at scales and purities that allow their clinical uses. Although direct isolation and purification of AMPs from natural sources are useful for their initial identification, the overall process is extremely laborious resulting in low yields and thus expensive to scale up (Harder et al. 1997). Solid phase peptide synthesis (SPPS) (Merrifield 1963) has been developed and used for decades to synthesize peptides in general (Bray 2003). However, scaling up peptide production using SPSS and especially for long peptide chains (>35 amino acids) have always been a major hurdle (Latham 1999). This is due to the inherent process complexity in SPPS that involves multiple chemical protection-deprotection steps for each introduced residue. The increased number of steps also increases the risk of producing peptides having errors in the sequence (Winkler and Tian 2015). Moreover, volumetric use of toxic reagents for its coupling and/or activation reaction increases with the number of peptide chain residues, posing adverse environment impacts.

Recombinant DNA technology offers more sustainable, scalable and cost-effective production of AMPs than the chemical-synthesis route due to its flexibility in genetically engineering microorganisms such as bacteria and yeasts (Müller et al. 2015). In this system, AMPs are generally expressed as fusion proteins to facilitate microbial production as well as simplified purification. Most of the carrier proteins are then cleaved and separated from AMPs. The available carrier proteins and cleavable linkers have been reviewed by Li et al. (Li 2011). Deng et al. reviewed different types of cell factories used to produce AMPs, including Escherichia coli, Bacillus subtilis, Pichia pastoris and Saccharomyces cerevisae (Deng et al. 2017). Müller et al. also reviewed various host strains with added methods for the isolation and purification of AMPs (Müller et al. 2015). However, high-cell-density fermentation of bacteria and yeasts in bioreactor to achieve large-scale production of AMPs has not been reviewed. 
In this Mini Review, recent progress in the large-scale recombinant production of AMPs after fusion of the peptides with carrier proteins is summarized. The review starts with selection of expression hosts and fusion tags that contribute to the successful production of AMPs. Specifically, the design of fusion proteins that facilitates microbial production, enhances solubility and expression yields as well as simplifies purification will be discussed. Chromatography and nonchromatography approaches that have been developed to purify the fusion proteins will be explored along with subsequent cleavage, isolation and purification of AMPs from the fusion proteins. Finally, scale-up manufacturing of AMPs will be described.

\section{Recombinant production of antimicrobial peptides}

Advances in genomics, proteomics, and bioinformatics reveal properties of AMPs which determines their biosynthesis strategies. In general, AMPs possessing high positive-charges and low molecular-weight are inherently bactericidal and prone to undergo proteolytic degradation in vivo. Some AMPs require the presence of disulfide bonds as well as certain hydrophobic levels to form structurally correct $\beta$-sheet, mixtures of $\alpha$-helix and $\beta$-sheet, or $\alpha$-helix, which would then enable them to optimally perform antimicrobial functions. Moreover, because of the unique specificity, some AMPs exhibit toxicity either to prokaryotics or to eukaryotics. Based on these properties, host organisms and plasmid library can then be rationally selected and designed enabling the production of functional recombinant AMPs with improved expression yields (Fig. 1). The selection of fusion tags and a combination thereof are highly important that contribute largely on their expression yields. However, there is no general rules in selecting expression hosts, plasmid features, and fusion tags for producing a given fusion protein-AMP with guaranteed maximum productivity. Therefore, it is important that expression screening is conducted using different combinations of microorganisms and plasmid libraries (Schreiber et al. 2017), and examined in a trial-and-error type approach.

\section{Figure 1}

\section{Expression hosts}

Escherichia coli (E. coli) is undoubtedly the mostly used microbial cell factory for production of recombinant AMPs. Its genetic configuration is well documented and has proven outstanding for easy genetic manipulation of prokaryotic expression systems. In this regards, E. coli strain BL21(DE3) is commonly used host strain as it is deficient of proteases (i.e., ompT and lon) that may lead to protein degradation (Sørensen and Mortensen 2005). E. coli strains Origami or Rosetta-gami have also been used especially for producing AMPs rich in disulfide bridges, for example, divercin V41 (Richard et al. 2004). These two strains contain negative mutation in both thioredoxin reductase (trxB) and glutathione reductase (gor) genes that make them unable to create a reducing environment in cytoplasm that enhances disulfide bond formation. On the other hand, E. coli BL21(DE3) fails to express the fusion protein of AMP containing disulfide bonds and, instead, formed protein aggregates (Panteleev and Ovchinnikova 2017). An alternative way to produce disulfide-rich fusion proteins is by co-expressing the signal sequence MalE for targeting the fusion proteins to the periplasm where the natural machinery for disulfide bond formation is located (Klint et al. 2013). Other strains of E. coli that have been used to produce recombinant AMPs, sonorensin and EC-hepcidin3, are Rosetta 2 (Chopra et al. 2014) and Rosetta (DE3) (Qu et al. 2013), respectively. Both Rosetta 2 and Rosetta (DE3) are the derivative of BL21 that contains codons rarely used in E. coli i.e., AGG, CCC, and GGA (Deng et al. 2017). Rare codons can negatively impact the biosynthesis of recombinant proteins, including mistranslational amino acid substitution, frameshifting events or premature translational termination (Sørensen and Mortensen 2005). Geneart AG technology (Regensburg, Germany) uses multi-parameter algorithms to minimize the use of rare codons. 
Bacillus subtilis (B. subtilis) has also been used as an alternative prokaryotic expression system to E. coli to produce AMPs including plectasin (Zhang et al. 2015a), cathelicidin (Luan et al. 2014), and hybrid cecropin A-melittin (Ji et al. 2017). B. subtilis has rapid growth rate and facilitates simpler protein purification as it secretes recombinant proteins directly into culture media, thus, avoiding cell-disruption step. Moreover, B. subtilis strain WB800N is deficient in eight extracellular proteases and therefore is usually used to produce AMPs. The drawback of this system is that the expression yield is sometimes low as compared to E. coli. For example, the yield of plectasin when expressed in B. subtilis (Zhang et al. 2015a) was three times lower than that in E. coli (Chen et al. 2015).

Pichia pastoris (P. pastoris) has recently gained popularity as an eukaryotic expression host for the production of AMPs. The advantages of $P$. pastoris as compared to E. coli are that it facilitates extracellular expression of AMPs and most posttranslational modifications, including disulfide bond formation, $\mathrm{O}$ - and N-glycosylation and processing of signal sequences correctly (Müller et al. 2015). Similar to E. coli, codon optimization in P. pastoris is needed to avoid translational errors (Meng et al. 2017).

\section{Fusion tags}

Design of fusion proteins by genetically linking AMPs to fusion tags (Fig. 2) is highly important for both their successful production and their effective purification. By expressing AMPs in a form of fusion proteins, the toxicity challenges which lead to intracellular proteolysis especially in prokaryotic expression systems can be addressed since fusion proteins increase the overall molecular weight and decrease the net charges to a point that is susceptible for microorganisms. To date, up to 30 fusion tags with different structures and functions have been used in the production of recombinant proteins. The characteristics of each fusion tag have been reviewed (Bell et al. 2013; Chen et al. 2013; Li et al. 2012; Li 2010; Pina et al. 2014; Young et al. 2012). It is not uncommon to fuse more than one tag to an AMP (Table 1). In fact, a combination of fusion tags (i.e., an affinity tag, a cleavage site, and/or a spacer) is actually critical for facilitating effective purification of fusion proteins and subsequent cleavage and separation of AMPs from the fusion tags. Common designs of fusion proteins expressing AMPs are presented in Fig. 2.

\section{Table 1}

Figure 2

The fusion tag SUMO (small ubiquitin-related modifier Smt3, 101 aa, $11.60 \mathrm{kDa}$ ) is usually used in conjunction with affinity tag hexahistidine ( $\mathrm{His}_{6}$ ) at its N-terminus (construction \#1, Fig. 2). The His-tag facilitates purification of fusion proteins using affinity chromatography. On the other hand, SUMO protein enhances the solubility of fused AMPs through the peripheral hydrophilic and central hydrophobic core structure (Yadav et al. 2016). The use of SUMO mostly does not require a cleavage site, as the conformation of SUMO is recognized by SUMO protease to cleave. Similar to SUMO, TrX (thioredoxin A, 109 aa, $11.68 \mathrm{kDa}$ ) is also used in combination with His 6 (construction \#2, Fig. 2). The affinity tag is usually located at the C-terminus of Trx as it ends in a rigid, solvent accessible $\alpha$-helix (Corsini et al. 2008). A fusion protein with Trx requires a specific sequence for chemical/enzymatic cleavage. Fusion tags such as GST (glutathione Stransferase, 211 aa, $26.00 \mathrm{kDa}$ ) and MBP (maltose-binding protein, 396 aa, $42.00 \mathrm{kDa}$ ) exhibit dual functionality as both solubility enhancer and affinity tags for chromatography purification since they are able to bind to glutathione and amylose resin, respectively (construction \#3, Fig. 2). Sometimes His-tag is added at the N-terminus of MBP (construction \#2, Fig. 2, Table 1) to facilitate the selection of two different chromatographic-purification methods. The use of high molecular weight tag like GST and MBP often decreases the risk of obtaining inclusion bodies when the tagged AMPs are overexpressed, although they may pose metabolic burden to the expression hosts due to its size and thus resulting in a low expression yield of the fusion proteins. 
DAMP4 (98 aa, $11.1 \mathrm{kDa}$ ) has emerged as a new, attractive fusion tag for the production of AMPs (construction \#4, Fig. 2) including pexiganan (Table 1). Computational study of DAMP4 confirmed that it is a four-helix bundle protein where most of the hydrophobic region is buried in the core while the hydrophilic part exposed to the solution (Schaller et al. 2015). This protein conformation makes DAMP4 an excellent candidate for enhancing solubility of the fused AMP, as well as facilitating purification without the use of expensive chromatography tools (see "Purification of fusion proteins”). An additional sequence is required as a spacer between DAMP4 and pexiganan to provide sufficient flexibility for pexiganan to kill pathogenic bacteria while still linking to DAMP4, which would otherwise difficult to achieve (Sun et al. 2018b). Setting the post-induction temperature to $25^{\circ} \mathrm{C}$ rather than $37^{\circ} \mathrm{C}$ is highly important to maintain the conformation of pexiganan, hence its antimicrobial activity. DAMP4 itself has no antimicrobial activity (Sun et al. 2018a; Zhao et al. 2015). Therefore, the removal of DAMP4 can be exempt, decreasing thus the overall costs of the purification process.

In parallel comparison, low molecular-weight tags such as Trx and SUMO can induce the soluble expression of plectasin in E. coli with the yield higher than that of using a high-molecular-weight tag like GST (Chen et al. 2015). Human AMP such as LL-37 can be overexpressed in E. coli with a high yield using dual fusion-tag SUMO-Trx rather than separately using either SUMO or Trx (Li 2013a). Vu et al. compared the use of several different fusion tags separately to express crotamine having three disulfide bonds (Table 1), including His 6 , Trx, SUMO, GST and MBP, and varied the expression temperatures to improve solubility (Vu et al. 2014). The production of crotamine was enhanced through the use of MBP tag as compared to other fusion tags demonstrating highest yield and solubility at both 20 and $37^{\circ} \mathrm{C}$ and correct conformation. MBP tag also proved effective in producing human $\beta$-defensin 25 (hBD25) and human $\beta$-defensin 28 (hBD28) in E. coli which were unable to express using GST and Trx fusion proteins (Li and Leong 2011; Tay et al. 2010). However, the fusion protein was produced mostly as soluble aggregates which required denaturation-reduction and subsequent refolding steps to achieve full antimicrobial activity.

Despite the aforementioned fusion-protein design, the combinations of fusion tags are not universal and must be used in a case-by-case basis depending also on the AMP properties to achieve high yield (Fig. 1). The aim is to determine which combination of fusion tags could result in highest expression yield. For example, expression of tachyplesin I as a fusion protein with His8-Trx resulted in inclusion body despite the fact that Trx is a solubility-enhancer tag (Panteleev and Ovchinnikova 2017). Schreiber et al. conducted high-throughput expression screening in 96-well plates using either E. coli or P. pastoris to produce AMPs with different properties: (1) IMPI (7.7 kDa, five disulfide bonds), (2) BR021 (8.4 kDa, toxic to E. coli), and (3) AFP (8.2 kDa, no disulfide bond, non-toxic to the hosts) (Fig. 3) (Schreiber et al. 2017). In general, E. coli was able to express all the AMPs with significantly higher yields than that of P. pastoris. The plasmid library consisted of 27 different expression plasmids (Fig. 3A). Three promoters (T7/lac, T5/lac and araBAD) were combined with a His 6 tag and either GST or Trx as a solubility tag (or no solubility tag) inclusive of a thrombin cleavage site at the N-terminal of the AMPs. IMPI and BR021 fused to $\mathrm{His}_{6}$-Trx can be produced in highest yield when induced by T7/lac promoter in E. coli Rosetta-gami 2 (DE3)pLysS and E. coli BL21(DE3), respectively, although the latter was expressed as an inclusion body. AFP fused to the GST tag could be produced as a soluble fusion protein using E. coli BL21(DE3).

\section{Figure 3}

\section{Purification of fusion proteins}

The methods and conditions used for the purification of fusion proteins containing AMPs depend on the expression host organisms as well as on the fusion tags (Table 1). Unlike B. subtilis and P. pastoris, purification of target proteins from $E$. coli normally requires disruption of the cells to recover the target proteins from cytoplasmic or periplasmic space of 
the bacteria using, for example, sonication, high pressure homogenization or bead mills (reviewed in (Middelberg 2012)), and followed by separation of the lysate from the cells. This section focuses on the purification of fusion proteins after being separated from cells. The use of affinity tags like His, GST and MBP (Table 1) enables protein purification using chromatography platform. Non-chromatographic methods have emerged as alternatives to chromatography approaches in protein purification and comprise simple and inexpensive heating and salting-out precipitation.

\section{Chromatography-based purification}

His tag is the most preference affinity tag used in the production of AMPs in the last five years (Table 1). Inclusion of His-tag enables different fusion proteins to be purified from crude cell extract using common immobilized metal-affinity chromatography (IMAC) method. Nitrilotriacetic acid (NTA) is usually used as a ligand for immobilizing metal ions $\mathrm{Ni}^{2+}$ (Ni-NTA resin) which binds histidine residues reversibly under both native and denaturing conditions. The length of His tag may vary with the six-residue long, His6, as the most common one. Hiss tag has also been used to purify, for example, the antimicrobial peptides LL-37 (Li 2013a) and tachyplesin I (Panteleev and Ovchinnikova 2017) which binds more strongly as compared to their shorter counterpart under the standard binding and elution conditions. This is advantageous as higher concentration of imidazole can be used during loading and washing to prevent co-purification of host protein contaminants. Further increasing the imidazole concentration enables elution of the His-tagged proteins.

MBP is an affinity tag that can bind specifically to amylose resin under physiological conditions, with mild elution performed using maltose. However, MBP tag tends to be used for enhancing solubility of the fusion proteins rather than for facilitating purification (Table 1). His 6 tag was used in conjunction with MBP to allow the purification of crotamine (Vu et al. 2014) and ORBK (Li et al. 2014) using IMAC. It is likely that components in the cell lysate used for cell lysis (such as detergents) may interfere with the hydrophobic interactions of MBP, as the structure and function of MBP largely depend on its aliphatic features. Unlike MBP, GST is used as an affinity tag for the purification of fusion AMPs. Palustrin2CE (Sun et al. 2012) and dermaseptin S4 (Song et al. 2014) have been purified using GST-based affinity chromatography. The purification method is based on the binding of GST tagged protein to the glutathione ligand coupled to a matrix. The target protein can be eluted under mild, non-denaturing conditions by the addition of reduced glutathione to the elution buffer.

Purification of fusion proteins has been relying heavily on chromatography approaches in which its cost alone account for more than $70 \%$ of the total downstream-processing cost (Azevedo et al. 2009). This is due to limited capacity and diffusion rate across chromatography supports, resulting in very long cycle times, coupled with the use of a large amount of buffer solution during equilibration, loading, washing, and elution steps. The purification yield severely suffers as a result of these multistep processes. In case of GST affinity chromatography, the binding kinetics of GST to glutathioneSepharose resin has been demonstrated to be extremely slow which would be a limiting factor for large-scale production (Hunt 2005). In IMAC, high concentration of nickel ions is always needed to charge the resin prior to use as the metal ions are stripped off from the resin to enable reuse, which is time consuming and not environmentally sustainable as well. An alternative way to minimize the utilities of chromatography tools could be an invaluable approach to purify fusion proteins as long as the final purity is not compromised.

\section{Non-chromatography-based purification}

A few fusion tags has made non-chromatography based purification of fusion protein possible, that is, by using a combined elastin-like polypeptide (ELP) and intein (Müller et al. 2015; Sousa et al. 2016), and four-helix bundle protein DAMP4 (Sun et al. 2018a; Sun et al. 2018b; Wibowo et al. 2017; Wibowo et al. 2015; Zhao et al. 2015). 
For ELP-intein fusion tags, ELP can switch between soluble and aggregate forms (depending on salt concentration and temperature) to isolate fusion proteins (Urry et al. 1985), whereas intein allows for self-cleavage (depending on pH, redox or temperature shifts) (Wood et al. 1999). In a typical process (Müller et al. 2015; Sousa et al. 2016), fusion ELPintein containing an AMP can be precipitated by increasing the temperature above the transition temperature $\left(\mathrm{T}_{\mathrm{t}}\right)$ of the ELP (ca. $30-40^{\circ} \mathrm{C}$ ) in the presence of a high concentration of $\mathrm{NaCl}$, hence separated from most soluble contaminants. Subsequent decrease in the temperature below $\mathrm{T}_{\mathrm{t}}\left(\mathrm{ca} .4^{\circ} \mathrm{C}\right.$ ) in a low concentration of $\mathrm{NaCl}$ re-solubilizes the fusion protein. This precipitation-re-solubilization cycle can be repeated as necessary to obtain sufficiently pure products.

DAMP4-based fusion protein is able to maintain its high stability and solubility against high temperature (up to $110^{\circ} \mathrm{C}$ ) and high concentration of sodium sulfate (Dimitrijev Dwyer et al. 2014), where most protein contaminants are precipitated, due to the four-helix bundle structure of DAMP4 that strongly interlocks its hydrophobic residues in the core (Wibowo et al. 2015). Further increasing the sodium sulfate concentration decreases the target-protein solubility, hence, precipitates enabling isolation (Wibowo et al. 2017). After re-solubilization in a simple buffer (low salt concentration), DAMP4-pexiganan with high purity can be obtained. Importantly, this fusion protein can be directly used as an antimicrobial agent without releasing the pexiganan from the inactive DAMP4, showing the same minimum inhibitory concentration (MIC) with the chemically-synthetized pexiganan (Sun et al. 2018b). This was made possible through the use of a long and flexible linker coupled with engineered bioprocess (i.e., low post-induction temperature) which allowed for the pexiganan to maintain its active conformationality even when it is still in the fusion form. In this way, the multisteps of cleavage, isolation and separation of AMPs from fusion protein can be completely avoided which ultimately result in high yield and low cost. To scale up this precipitation-based purification method, it is recommended that centrifugation steps are replaced with a tangential-flow-filtration method, a common separation technology workhorse in industry (Zydney 2016).

\section{Recovery of antimicrobial peptides from the fusion proteins}

Release of AMPs from the fusion proteins is often necessary when the presence of fusion tags influences the structure and hence function of the AMPs. Site-specific sequences are therefore included between the tags and AMPs (Fig. 2), and then cleaved with site-specific chemicals or proteases allowing for the release of active AMPs.

Cleavage methods using chemicals can be more efficient and less expensive than enzymatic cleavage (Gibbs et al. 2004). $\mathrm{CNBr}$ or formic acid are usually used to cleave at the methionine residue $(\mathrm{M} \uparrow$ ) or in between aspartic acid and proline ( $\mathrm{D} \uparrow \mathrm{P}$ ) residues, respectively (Table 1 ). However, recognition sites of one or two amino acids are rather unspecific, having the risk of secondary cleavage. The harsh conditions often result in side chain modification of AMPs (Toennies and Homiller 1942). In addition, accumulation of toxic chemicals when used in a larger scale is not environmentally sustainable.

Enzymatic cleavage is more specific, and cleavage is usually achieved under carefully controlled mild reaction conditions. There are several proteases that are commonly used for cleavage of AMPs from fusion proteins (Table 1). Its drawback is that it requires a high ratio of enzymes to proteins, and long incubation time for complete tag removal. Protease that can be produced and purified from recombinant bacteria is therefore advantageous in reducing the overall purification costs. Since the cleavage reaction is dependent on the structure of the fusion protein, it is important that accessibility of the recognition site to protease is well preserved. For example, Tay et al. added a spacer sequence to separate MBP from the tobacco etch virus (TEV) protease cleavage site to prevent the large MBP fusion tag from blocking TEVp accessibility to the cleavage site (Tay et al. 2010). This TEV protease is highly specific recognizing ENLYFQ $\uparrow G$ and cleaves between glutamine and serine efficiently at low temperatures. SUMO is recognized by SUMO protease $(S$. 
cerevisiae Ulp1) on its conformationality. This type of protease is able to cleave at the N-terminus of fused AMPs irrespective of the sequence (except proline) under a wide range of $\mathrm{pH}$ (5.5-10.5), temperatures $\left(4-37^{\circ} \mathrm{C}\right)$, and high concentration of denaturing agents such as urea (Young et al. 2012). The latter is useful to facilitate purification of SUMOtagged proteins when produced as inclusion bodies. Unlike SUMO protease, proteases such as thrombin, enterokinase and TEV protease result in one or two amino acids residues from the cleavage site at the N-terminus of the AMPs (Table 1). The AMPs containing these residues should undergo careful characterization of the overall structure and function using, for example, circular dichroism spectrophotometer (structure) and minimum inhibitory concentration test (function). Despite their specificity, there have been cases that enterokinase, thrombin and factor Xa cause secondary cleavage, resulting in protein degradation and lower yields (Arnau et al. 2006). Characterization using sodium dodecyl polyacrylamide gel electrophoresis and/or mass spectrophotometer could assist in determining correct molar mass of the AMPs in interest.

The AMPs can be recovered from the mixture for ensuring complete removal of the chemicals or proteases that might negatively influence the biological activity of the AMPs. Purification of AMPs is rationally designed based on the characteristics of different tags and AMPs in the post-cleavage mixture. Immobilized metal-affinity chromatography is most commonly used technique to bind His-tagged fusion proteins after the cleavage step, and the AMPs can be recovered from the flow-through fraction (Luan et al. 2014; Wei et al. 2018; Zhang et al. 2014; Zhang et al. 2015a). Size exclusion chromatography (SEC) separates the cleaved AMP from fusion tags based on the size difference in which the size gap should be large enough to allow better resolution (Sun et al. 2018a; Tao et al. 2014; Yi et al. 2015). Reversed-phased high-performance liquid chromatography (RP-HPLC) takes advantage of high hydrophobic level of AMPs as compared to their fusion tags (Panteleev and Ovchinnikova 2017). The captured AMPs to the long-chain-hydrocarbon resin can then be eluted by increasing concentration of organic solvent such as acetonitrile to weaken the hydrophobic forces. RPHPLC is also useful as a final polishing step of the AMP after SEC to improve purity, although the purification yield was severely compromised (Feng et al. 2015). The levels of purity and yield are always a trade off, and must be considered when designing downstream-processing methods. Cationic exchange chromatography has been used to bind AMPs based on their ionic properties (Che et al. 2016; Meng et al. 2016a). Prior to loading, the sample should be dialysed to reduce the salt concentration to a level that would not interfere the electrostatic interactions between the AMP and the chromatographic resin. Elution of the bonded AMP from the resin can therefore be achieved by increasing salt concentrations.

Simple non-chromatographic methods to recover AMPs, such as pexiganan (Sun et al. 2018a) and human $\beta$-defensin 28 (Tay et al. 2010), from the fusion proteins DAMP4 and MBP, respectively, have been used as alternatives to chromatography approaches. The separation is mostly based on the difference in the properties of the fusion protein components such as isoelectric points, solubility, etc. (Sun et al. 2018a; Tay et al. 2010). This allowed the addition of hydrochloric acid to recover AMPs from the other cleavage components. While the fusion tags and other cleavage proteases were precipitated, the AMPs remained soluble enabling their recovery by centrifugation or filtration. A purity as high as 95\% can be achieved using this method (Sun et al. 2018a; Tay et al. 2010). The non-chromatography approaches have proved to be an economical means to recover AMPs rapidly with high purity. These are important traits (speed and cost) and would be the commercial driver when developing new antimicrobial products. Further process development will be to optimize expression yields through the use of fermenter, maximizing recovery yields and volumetric productivity of the AMPs.

\section{Scale up production}


Once the expression system and purification methods have been developed using AMPs produced in shake flasks, high cell density culture can be carried out using fermenters to further increase the protein product titer. In the past five years, there are several published attempts to produce AMPs using fermenters at scales and productivity larger than that of using shake flasks aforementioned. E. coli has been utilized to produce AMPs including plantaricin E (Pal and Srivastava 2015) and Pa-MAP 2 (Sousa et al. 2016), as well as P. pastoris for MP1102 (Zhang et al. 2015b), NZ17074 (Wang et al. 2014), and apidaecin (Cao et al. 2018; Chen et al. 2017), and B. subtilis for gageomacrolactins (Tareq et al. 2013). Unlike growing cells in shake-flasks, critical parameters are controlled in fermenters including temperature, $\mathrm{pH}$, and dissolved oxygen (DO). For example, the limited availability of DO when cells grow to high density can be alleviated by flowing oxygen-enriched air or pure oxygen into the cultured cells. This is also beneficial for minimizing the formation of acetate during cultivation - a fermentation by-product of E. coli which can decrease cell-growth rate (Sousa et al. 2016). Optimizing media composition and feeding strategies also play important roles in facilitating high cell density and high productivity of recombinant fusion protein-AMPs.

In general, cell-growth media require carbon source, nitrogen source, salts, minerals and some growth factors to reach an optimal cell density and high level of recombinant fusion proteins (Schmidt 2005). It is crucial that these components are selectively formulated to contain not only necessary components, but also optimal concentrations to avoid inhibition of cell growth (Lee 1996). A rich nutrient environment can be provided by complex media containing ingredients with completely unknown composition (such as yeast extract or tryptone), by chemically-defined media (or synthetic media) composed of chemicals of known identities and concentrations, or by semi-defined media formulated mostly with defined chemicals (except for one or two complex nutrients). Sousa et al. used and compared semi-defined medium, terrific broth (TB), with defined media to produce antimicrobial fusion protein in E. coli and demonstrated that the cells grew in TB medium gave higher productivity rate overtime and thus higher expression yield of $117 \mathrm{mg} / \mathrm{L}$ as compared to $68 \mathrm{mg} / \mathrm{L}$ in defined media (Sousa et al. 2016). Semi-defined media have also been used in cultivating yeast for the production of AMPs. Chen et al. further increased the cell density of $P$. pastoris and, hence, the expression yield of apidaecin by adding yeast extract and tryptone into the chemically-defined basal salt media (Chen et al. 2017).

Feeding strategies like fed-batch fermentation mode can be implemented to achieve high cell density culture by continuously supplying essential nutrients to sustain and control cell growth to reach high protein productivity. The DO-stat method is commonly used method based on the DO changes. DO is consumed by cells overtime, and the rise in DO is an indication of carbon source depletion. In fed-batch mode, a predetermined amount of concentrated feeding solution can then be fed into the bioreactor. In addition to achieving high cell density, these feedback-controlled feeding methods are advantageous in preventing the overfeeding of nutrients. Sousa et al. produced fusion protein containing antimicrobial Pa-MAP 2 in E. coli in a defined media using both batch and fed-batch fermentation modes (Fig. 4) (Sousa et al. 2016). In both modes, the DO levels were maintained at $20 \%$ to minimize the acetate production level, and the cells were induced at 8-h to start producing the recombinant protein. Unlike the batch mode, glucose was added from time to time in the fed-batch mode to further increase the growth of E. coli. Biomass of $E$. coli produced in the fed-batch was $18 \%$ higher than that of the batch mode, and this was accompanied by the increase in the total Pa-MAP 2 production by $23 \%$.

\section{Figure 4}

Despite the bioprocess developed in fermenters, the yields of AMPs produced in fermenters are not convincingly high as compared to that in shake flasks (Table 1). Although high cell density can be achieved, it does not always mean that high cell density correlates linearly with high protein yields. Obviously, there should be more effort in optimizing the parameters in fermenters to significantly enhance the yield, including oxygen transfer rate, air/oxygen flow rate, and medium composition, to evaluate important process parameters on a specific AMP product. Bioreactor design, 
including the impeller design and use of baffle, should also be optimized as large fermentation capacity could impose heat and mass transfer problems which then result in imbalanced and zonal distribution of DO, nutrient supply, $\mathrm{pH}$, heat and metabolites inside the bioreactor (Enfors et al. 2001). Furthermore, optimization of medium components is critical as well for enhanced AMPs production, that is, by analyzing the effects of different components and their interactions on cell growth, protein titer and quality (Huang et al. 2012). This can be achieved using either statistical analysis to predict optimum medium compositions (Weuster-Botz 2000) or E. coli chemostat culture (Yee and Blanch 1993). The latter can be carried out to identify specific nutritional and regulatory components by systematically adding or removing components at varied concentrations from chemically-defined media formulation and simultaneously determining the corresponding cellular responses. In this way, unpredictable results due to the complications in interactions among complex components can be minimized or at least more understandable.

\section{Conclusion}

To realize the great potential of AMPs in pharmaceutical and therapeutic applications, cost-effective and scalable methods for the production of active AMPs is of great significance. Conventional strategies for producing AMPs as recombinant peptides have encountered many difficulties such as low expression yield because of the toxicity AMPs to their bacterial hosts, low production yields due to tedious and multistep processes of releasing and purifying AMPs from fusion proteins, thus leading to difficulties in their scale-up production. Also, the laborious and trial-and-error approach is not viable for identifying the best expression constructs. High-throughput expression screening provides a promising platform to optimize plasmid features and expression hosts, thus enhancing protein expression yields that are suitable for large-scale AMP production. In terms of the subsequent AMP recovery from fusion proteins, non-chromatography methods offers an alternative strategy to achieve cost-effective protein purification. As there have been only a few active research groups working in this field, the progress of developing large-scale production of AMPs has been slow and non-systematic. Although there is still a long way to go from lab-scale research to industrial scale production of AMPs, more research efforts especially the involvement of pharmaceutical companies along with the advances of quantitative structure-activity relationship (QSAR) modelling, computer-aided design and high throughput screening will lead to significant technology advancement in this field. 


\section{Acknowledgments}

The authors acknowledge the research funding by the Australian Research Council (ARC) under Future Fellowship Project (FT140100726) and Discovery Project (DP150100798). C.-X Zhao acknowledges financial support from the award of the Australian Research Council (ARC) Future Fellowship (FT140100726).

\section{Compliance with ethical standards}

\section{Conflict of interests}

The authors declare no financial or commercial conflict of interest.

\section{Ethical statement}

This article does not contain any studies with human participants or animals performed by any of the authors.

\section{References}

Abou Aleinein R, Hamoud R, Schafer H, Wink M (2013) Molecular cloning and expression of ranalexin, a bioactive antimicrobial peptide from Rana catesbeiana in Escherichia coli and assessments of its biological activities. Appl Microbiol Biotechnol 97(8):3535-3543. https://doi.org/10.1007/s00253-012-4441-1

Arnau J, Lauritzen C, Petersen GE, Pedersen J (2006) Current strategies for the use of affinity tags and tag removal for the purification of recombinant proteins. Protein Expr Purif 48(1):1-13. https://doi.org/10.1016/j.pep.2005.12.002

Azevedo AM, Rosa PAJ, Ferreira IF, Aires-Barros MR (2009) Chromatography-free recovery of biopharmaceuticals through aqueous two-phase processing. Trends Biotechnol 27(4):240-247. https://doi.org/10.1016/j.tibtech.2009.01.004

Bahar A, Ren D (2013) Antimicrobial peptides. Pharmaceuticals 6(12):1543. https://doi.org/10.3390/ph6121543

Bell MR, Engleka MJ, Malik A, Strickler JE (2013) To fuse or not to fuse: what is your purpose? Protein Sci 22(11):14661477. https://doi.org/10.1002/pro.2356

Bray BL (2003) Large-scale manufacture of peptide therapeutics by chemical synthesis. Nat Rev Drug Discov 2:587. https://doi.org/10.1038/nrd1133

Cao J, de la Fuente-Nunez C, Ou RW, Torres MDT, Pande SG, Sinskey AJ, Lu TK (2018) Yeast-based synthetic biology platform for antimicrobial peptide production. ACS Synth Biol 7(3):896-902. https://doi.org/10.1021/acssynbio.7b00396

Casciaro B, Dutta D, Loffredo MR, Marcheggiani S, McDermott AM, Willcox MD, Mangoni ML (2018) Esculentin-1a derived peptides kill Pseudomonas aeruginosa biofilm on soft contact lenses and retain antibacterial activity upon immobilization to the lens surface. Biopolymers 110(5):e23074. https://doi.org/10.1002/bip.23074

Che YY, Lu YH, Zha XD, Huang HQ, Yang PL, Ma LJ, Xu XJ (2016) Higher efficiency soluble prokaryotic expression, purification, and structural analysis of antimicrobial peptide G13. Protein Expr Purif 119:45-50. https://doi.org/10.1016/j.pep.2015.11.006

Chen X, Li J, Sun H, Li S, Chen T, Liu G, Dyson P (2017) High-level heterologous production and functional secretion by recombinant Pichia pastoris of the shortest proline-rich antibacterial honeybee peptide apidaecin. Sci Rep 7(1):14543. https://doi.org/10.1038/s41598-017-15149-3

Chen X, Shi JW, Chen R, Wen YA, Shi Y, Zhu Z, Guo SW, Li L (2015) Molecular chaperones (TrxA, SUMO, Intein, and GST) mediating expression, purification, and antimicrobial activity assays of plectasin in Escherichia coli. Biotechnol Appl Biochem 62(5):606-614. https://doi.org/10.1002/bab.1303 
Chen X, Zaro JL, Shen W-C (2013) Fusion protein linkers: property, design and functionality. Adv Drug Deliv Rev 65(10):1357-1369. https://doi.org/10.1016/j.addr.2012.09.039

Chopra L, Singh G, Choudhary V, Sahoo DK (2014) Sonorensin: an antimicrobial peptide, belonging to the heterocycloanthracin subfamily of bacteriocins, from a new marine isolate, Bacillus sonorensis MT93. Appl Environ Microbiol 80(10):2981-2990. https://doi.org/10.1128/aem.04259-13

Corsini L, Hothorn M, Scheffzek K, Sattler M, Stier G (2008) Thioredoxin as a fusion tag for carrier-driven crystallization. Protein Sci 17(12):2070-2079. https://doi.org/10.1110/ps.037564.108

Deng T, Ge H, He H, Liu Y, Zhai C, Feng L, Yi L (2017) The heterologous expression strategies of antimicrobial peptides in microbial systems. Protein Expr Purif 140:52-59. https://doi.org/10.1016/j.pep.2017.08.003

Dimitrijev Dwyer M, Brech M, Yu L, Middelberg APJ (2014) Intensified expression and purification of a recombinant biosurfactant protein. Chem Eng Sci 105:12-21. https://doi.org/10.1016/j.ces.2013.10.024

Dutta D, Kamphuis B, Ozcelik B, Thissen H, Pinarbasi R, Kumar N, Willcox MDP (2018) Development of silicone hydrogel antimicrobial contact lenses with Mel4 peptide coating. Optom Vis Sci 95(10):937-946. https://doi.org/10.1097/opx.0000000000001282

Eckert R (2011) Road to clinical efficacy: challenges and novel strategies for antimicrobial peptide development. Future Microbiol 6(6):635-651. https://doi.org/10.2217/fmb.11.27

Enfors SO, Jahic M, Rozkov A, Xu B, Hecker M, Jürgen B, Krüger E, Schweder T, Hamer G, O'Beirne D, NoisommitRizzi N, Reuss M, Boone L, Hewitt C, McFarlane C, Nienow A, Kovacs T, Trägårdh C, Fuchs L, Revstedt J, Friberg PC, Hjertager B, Blomsten G, Skogman H, Hjort S, Hoeks F, Lin HY, Neubauer P, van der Lans R, Luyben K, Vrabel P, Manelius A (2001) Physiological responses to mixing in large scale bioreactors. J Biotechnol 85(2):175-185. https://doi.org/10.1016/S0168-1656(00)00365-5

Feng XJ, Xu WS, Qu P, Li XC, Xing LW, Liu D, Jiao J, Wang J, Li ZQ, Liu CL (2015) High-yield recombinant expression of the chicken antimicrobial peptide fowlicidin-2 in Escherichia coli. Biotechnol Prog 31(2):369-374. https://doi.org/10.1002/btpr.2041

Ganz T (2003) The role of antimicrobial peptides in innate immunity. Integr Comp Biol 43(2):300-304. https://doi.org/10.1093/icb/43.2.300

Gaspar D, Veiga AS, Castanho MARB (2013) From antimicrobial to anticancer peptides. A review. Front Microbiol 4(294) https://doi.org/10.3389/fmicb.2013.00294

Gibbs GM, Davidson BE, Hillier AJ (2004) Novel expression system for large-scale production and purification of recombinant class IIa bacteriocins and its application to piscicolin 126. Appl Environ Microbiol 70(6):32923297. https://doi.org/10.1128/AEM.70.6.3292-3297.2004

Harder J, Bartels J, Christophers E, Schröder JM (1997) A peptide antibiotic from human skin. Nature 387:861. https://doi.org/10.1038/43088

Herbel V, Schafer H, Wink M (2015) Recombinant production of snakin-2 (an antimicrobial peptide from tomato) in Ecoli and analysis of its bioactivity. Molecules 20(8):14889-14901. https://doi.org/0.3390/molecules200814889

Hou HH, Yan WL, Du KX, Ye YJ, Cao QQ, Ren WH (2013) Construction and expression of an antimicrobial peptide scolopin 1 from the centipede venoms of Scolopendra subspinipes mutilans in Escherichia coli using SUMO fusion partner. Protein Expr Purif 92(2):230-234. https://doi.org/10.1016/j.pep.2013.10.004

Huang C-J, Lin H, Yang X (2012) Industrial production of recombinant therapeutics in Escherichia coli and its recent advancements. J Ind Microbiol Biotechnol 39(3):383-399. https://doi.org/10.1007/s10295-011-1082-9

Hunt I (2005) From gene to protein: a review of new and enabling technologies for multi-parallel protein expression. Protein Expr Purif 40(1):1-22. https://doi.org/10.1016/j.pep.2004.10.018 
Ji S, Li W, Baloch AR, Wang M, Li H, Cao B, Zhang H (2017) Efficient biosynthesis of a cecropin A-melittin mutant in Bacillus subtilis WB700. Sci Rep 7:40587. https://doi.org/10.1038/srep40587

Klint JK, Senff S, Saez NJ, Seshadri R, Lau HY, Bende NS, Undheim EAB, Rash LD, Mobli M, King GF (2013) Production of recombinant disulfide-rich venom peptides for structural and functional analysis via expression in the periplasm of E. coli. PLoS One 8(5):e63865. https://doi.org/10.1371/journal.pone.0063865

Latham PW (1999) Therapeutic peptides revisited. Nat Biotechnol 17:755. https://doi.org/10.1038/11686

Lee SY (1996) High cell-density culture of Escherichia coli. Trends Biotechnol 14(3):98-105. https://doi.org/10.1016/0167-7799(96)80930-9

Li P, Li X, Saravanan R, Li CM, Leong SSJ (2012) Antimicrobial macromolecules: synthesis methods and future applications. RSC Adv 2(10):4031-4044. https://doi.org/10.1039/C2RA01297A

Li X, Leong SSJ (2011) A chromatography-focused bioprocess that eliminates soluble aggregation for bioactive production of a new antimicrobial peptide candidate. J Chromatogr A 1218(23):3654-3659. https://doi.org/10.1016/j.chroma.2011.04.017

Li Y (2010) Carrier proteins for fusion expression of antimicrobial peptides in Escherichia coli. Biotechnol Appl Biochem 54(1):1-9. https://doi.org/10.1042/BA20090087

Li Y (2011) Recombinant production of antimicrobial peptides in Escherichia coli: a review. Protein Expr Purif 80(2):260-267. https://doi.org/10.1016/j.pep.2011.08.001

Li Y, Wang J, Yang J, Wan C, Wang X, Sun H (2014) Recombinant expression, purification and characterization of antimicrobial peptide ORBK in Escherichia coli. Protein Expr Purif 95:182-187. https://doi.org/10.1016/j.pep.2013.12.011

Li YF (2013a) Production of human antimicrobial peptide LL-37 in Escherichia coli using a thioredoxin-SUMO dual fusion system. Protein Expr Purif 87(2):72-78. https://doi.org/10.1016/j.pep.2012.10.008

Li YF (2013b) Recombinant production of crab antimicrobial protein scygonadin expressed as thioredoxin and SUMO fusions in Escherichia coli. Appl Biochem Biotechnol 169(6):1847-1857. https://doi.org/10.1007/s12010-013$\underline{0102-9}$

Lin CH, Pan YC, Liu FW, Chen CY (2017) Prokaryotic expression and action mechanism of antimicrobial LsGRP1 ${ }^{\mathrm{C}}$ recombinant protein containing a fusion partner of small ubiquitin-like modifier. Appl Microbiol Biotechnol 101(22):8129-8138. https://doi.org/10.1007/s00253-017-8530-z

Luan C, Zhang HW, Song DG, Xie YG, Feng J, Wang YZ (2014) Expressing antimicrobial peptide cathelicidin-BF in Bacillus subtilis using SUMO technology. Appl Microbiol Biotechnol 98(8):3651-3658. https://doi.org/10.1007/s00253-013-5246-6

Mai S, Mauger MT, Niu L-N, Barnes JB, Kao S, Bergeron BE, Ling J-Q, Tay FR (2017) Potential applications of antimicrobial peptides and their mimics in combating caries and pulpal infections. Acta Biomater 49:16-35. https://doi.org/10.1016/j.actbio.2016.11.026

Mangoni ML, McDermott AM, Zasloff M (2016) Antimicrobial peptides and wound healing: biological and therapeutic considerations. Exp Dermatol 25(3):167-173. https://doi.org/10.1111/exd.12929

Meng D-M, Dai H-X, Gao X-F, Zhao J-F, Guo Y-J, Ling X, Dong B, Zhang Z-Q, Fan Z-C (2016a) Expression, purification and initial characterization of a novel recombinant antimicrobial peptide Mytichitin-A in Pichia pastoris. Protein Expr Purif 127:35-43. https://doi.org/10.1016/j.pep.2016.07.001

Meng D-M, Zhao J-F, Ling X, Dai H-X, Guo Y-J, Gao X-F, Dong B, Zhang Z-Q, Meng X, Fan Z-C (2017) Recombinant expression, purification and antimicrobial activity of a novel antimicrobial peptide PaDef in Pichia pastoris. Protein Expr Purif 130:90-99. https://doi.org/10.1016/j.pep.2016.10.003 
Meng FQ, Zhao HZ, Zhang C, Lu FX, Bie XM, Lu ZX (2016b) Expression of a novel bacteriocin-the plantaricin Pln1-in Escherichia coli and its functional analysis. Protein Expr Purif 119:85-93. https://doi.org/10.1016/j.pep.2015.11.008

Merrifield RB (1963) Solid phase peptide synthesis. I. The synthesis of a tetrapeptide. J Am Chem Soc 85(14):21492154. https://doi.org/10.1021/ja00897a025

Middelberg APJ (2012) Releasing biopharmaceutical products from cells. In: Subramanian G (ed) Biopharmaceutical production technology. vol 1. Wiley-VCH Verlag GmbH \& Co. KGaA, Weinheim, Germany

Mishra B, Reiling S, Zarena D, Wang G (2017) Host defense antimicrobial peptides as antibiotics: design and application strategies. Curr Opin Chem Biol 38:87-96. https://doi.org/10.1016/j.cbpa.2017.03.014

Müller H, Salzig D, Czermak P (2015) Considerations for the process development of insect-derived antimicrobial peptide production. Biotechnol Prog 31(1):1-11. https://doi.org/10.1002/btpr.2002

Nguyen LT, Haney EF, Vogel HJ (2011) The expanding scope of antimicrobial peptide structures and their modes of action. Trends Biotechnol 29(9):464-472. https://doi.org/10.1016/j.tibtech.2011.05.001

Nordström R, Malmsten M (2017) Delivery systems for antimicrobial peptides. Adv Colloid Interface Sci 242:17-34. https://doi.org/10.1016/j.cis.2017.01.005

Onaizi SA, Leong SSJ (2011) Tethering antimicrobial peptides: current status and potential challenges. Biotechnol Adv 29(1):67-74. https://doi.org/10.1016/j.biotechadv.2010.08.012

Pal G, Srivastava S (2015) Scaling up the production of recombinant antimicrobial plantaricin E from a heterologous host, Escherichia coli. Probiotics Antimicrob Proteins 7(3):216-221. https://doi.org/10.1007/s12602-015-91937

Panteleev PV, Ovchinnikova TV (2017) Improved strategy for recombinant production and purification of antimicrobial peptide tachyplesin I and its analogs with high cell selectivity. Biotechnol Appl Biochem 64(1):35-42. https://doi.org/10.1002/bab.1456

Pina AS, Lowe CR, Roque ACA (2014) Challenges and opportunities in the purification of recombinant tagged proteins. Biotechnol Adv 32(2):366-381. https://doi.org/10.1016/j.biotechadv.2013.12.001

Qu H, Chen B, Peng H, Wang K (2013) Molecular cloning, recombinant expression, and antimicrobial activity of EChepcidin3, a new four-cysteine hepcidin isoform from Epinephelus coioides. Biosci Biotechnol Biochem 77(1):103-110. https://doi.org/10.1271/bbb.120600

Rezaei Javan R, van Tonder AJ, King JP, Harrold CL, Brueggemann AB (2018) Genome sequencing reveals a large and diverse repertoire of antimicrobial peptides. Front Microbiol 9(2012) https://doi.org/10.3389/fmicb.2018.02012

Richard C, Drider D, Elmorjani K, Marion D, Prévost H (2004) Heterologous expression and purification of active divercin V41, a class IIa bacteriocin encoded by a synthetic gene in Escherichia coli. J Bacteriol 186(13):42764284. https://doi.org/10.1128/JB.186.13.4276-4284.2004

Schaller A, Connors NK, Dwyer MD, Oelmeier SA, Hubbuch J, Middelberg APJ (2015) Computational study of elements of stability of a four-helix bundle protein biosurfactant. J Comput Aided Mol Des 29(1):47-58. https://doi.org/10.1007/s10822-014-9803-6

Schmidt FR (2005) Optimization and scale up of industrial fermentation processes. Appl Microbiol Biotechnol 68(4):425435. https://doi.org/10.1007/s00253-005-0003-0

Schreiber C, Müller H, Birrenbach O, Klein M, Heerd D, Weidner T, Salzig D, Czermak P (2017) A high-throughput expression screening platform to optimize the production of antimicrobial peptides. Microb Cell Fact 16(1):29. https://doi.org/10.1186/s12934-017-0637-5 
Song D, Chen Y, Li X, Zhu M, Gu Q (2014) Heterologous expression and purification of dermaseptin S4 fusion in Escherichia coli and recovery of biological activity. Prep Biochem Biotechnol 44(6):598-607. https://doi.org/10.1080/10826068.2013.835735

Sørensen HP, Mortensen KK (2005) Advanced genetic strategies for recombinant protein expression in Escherichia coli. J Biotechnol 115(2):113-128. https://doi.org/10.1016/j.jbiotec.2004.08.004

Sousa DA, Mulder KCL, Nobre KS, Parachin NS, Franco OL (2016) Production of a polar fish antimicrobial peptide in Escherichia coli using an ELP-intein tag. J Biotechnol 234:83-89. https://doi.org/10.1016/j.jbiotec.2016.07.021

Sun B, Wibowo D, Middelberg APJ, Zhao C-X (2018a) Cost-effective downstream processing of recombinantly produced pexiganan peptide and its antimicrobial activity. AMB Expr 8(1):6. https://doi.org/10.1186/s13568-018-0541-3

Sun B, Wibowo D, Sainsbury F, Zhao C-X (2018b) Design and production of a novel antimicrobial fusion protein in Escherichia coli. Appl Microbiol Biotechnol 102(20):8763-8772. https://doi.org/10.1007/s00253-018-9319-4

Sun Y, Li Q, Li Z, Zhang Y, Zhao J, Wang L (2012) Molecular cloning, expression, purification, and functional characterization of palustrin-2CE, an antimicrobial peptide of Rana chensinensis. Biosci Biotechnol Biochem 76(1):157-162. https://doi.org/10.1271/bbb.110672

Tao Y, Zhao DM, Wen Y (2014) Expression, purification and antibacterial activity of the channel catfish hepcidin mature peptide. Protein Expr Purif 94:73-78. https://doi.org/10.1016/j.pep.2013.11.001

Tareq FS, Kim JH, Lee MA, Lee H-S, Lee J-S, Lee Y-J, Shin HJ (2013) Antimicrobial gageomacrolactins characterized from the fermentation of the marine-derived bacterium Bacillus subtilis under optimum growth conditions. $\mathrm{J}$ Agric Food Chem 61(14):3428-3434. https://doi.org/10.1021/jf4009229

Tay DKS, Rajagopalan G, Li X, Chen Y, Lua LHL, Leong SSJ (2010) A new bioproduction route for a novel antimicrobial peptide. Biotechnol Bioeng 108(3):572-581. https://doi.org/10.1002/bit.22970

Toennies G, Homiller RP (1942) The oxidation of amino acids by hydrogen peroxide in formic acid. J Am Chem Soc 64(12):3054-3056. https://doi.org/10.1021/ja01264a518

Travkova OG, Moehwald H, Brezesinski G (2017) The interaction of antimicrobial peptides with membranes. Adv Colloid Interface Sci 247:521-532. https://doi.org/10.1016/j.cis.2017.06.001

Urry DW, Trapane TL, Prasad KU (1985) Phase-structure transitions of the elastin polypentapeptide-water system within the framework of composition-temperature studies. Biopolymers 24(12):2345-2356. https://doi.org/10.1002/bip.360241212

Ventola CL (2015) The antibiotic resistance crisis: Part 1: Causes and threats. P \& T 40(4):277-283.

Vu TTT, Jeong B, Yu J, Koo B-K, Jo S-H, Robinson RC, Choe H (2014) Soluble prokaryotic expression and purification of crotamine using an N-terminal maltose-binding protein tag. Toxicon 92:157-165. https://doi.org/10.1016/j.toxicon.2014.10.017

Wang G, Li X, Wang Z (2016) APD3: the antimicrobial peptide database as a tool for research and education. Nucleic Acids Res 44(D1):D1087-D1093. https://doi.org/10.1093/nar/gkv1278

Wang XJ, Wang XM, Teng D, Zhang Y, Mao RY, Wang JH (2014) Recombinant production of the antimicrobial peptide NZ17074 in Pichia pastoris using SUMO3 as a fusion partner. Lett Appl Microbiol 59(1):71-78. https://doi.org/10.1111/lam.12246

Wei XB, Wu RJ, Zhang LL, Ahmad B, Si DY, Zhang RJ (2018) Expression, purification, and characterization of a novel hybrid peptide with potent antibacterial activity. Molecules 23(6) https://doi.org/10.3390/molecules23061491

Weuster-Botz D (2000) Experimental design for fermentation media development: statistical design or global random search? J Biosci Bioeng 90(5):473-483. https://doi.org/10.1016/S1389-1723(01)80027-X 
Wibowo D, Yang G-Z, Middelberg APJ, Zhao C-X (2017) Non-chromatographic bioprocess engineering of a recombinant mineralizing protein for the synthesis of silica nanocapsules. Biotechnol Bioeng 114(2):335-343. https://doi.org/10.1002/bit.26079

Wibowo D, Zhao C-X, Middelberg APJ (2015) Interfacial biomimetic synthesis of silica nanocapsules using a recombinant catalytic modular protein. Langmuir 31(6):1999-2007. https://doi.org/10.1021/la504684g

Winkler DFH, Tian K (2015) Investigation of the automated solid-phase synthesis of a 38mer peptide with difficult sequence pattern under different synthesis strategies. Amino Acids 47(4):787-794. https://doi.org/10.1007/s00726-014-1909-6

Wood DW, Wu W, Belfort G, Derbyshire V, Belfort M (1999) A genetic system yields self-cleaving inteins for bioseparations. Nat Biotechnol 17:889. https://doi.org/10.1038/12879

Xie YG, Luan C, Zhang HW, Han FF, Feng J, Choi YJ, Groleau D, Wang YZ (2013) Effects of thioredoxin: SUMO and intein on soluble fusion expression of an antimicrobial peptide OG2 in Escherichia coli. Protein Peptide Lett 20(1):54-60. https://doi.org/10.2174/092986613804096775

Yadav DK, Yadav N, Yadav S, Haque S, Tuteja N (2016) An insight into fusion technology aiding efficient recombinant protein production for functional proteomics. Arch Biochem Biophys 612:57-77. https://doi.org/10.1016/j.abb.2016.10.012

Yee L, Blanch HW (1993) Defined media optimization for growth of recombinant Escherichia coli X90. 41(2):221-230. https://doi.org/10.1002/bit.260410208

Yi TH, Sun SY, Huang YB, Chen YX (2015) Prokaryotic expression and mechanism of action of alpha-helical antimicrobial peptide A20L using fusion tags. BMC Biotechnol 15 https://doi.org/10.1186/s12896-015-0189-X

Young CL, Britton ZT, Robinson AS (2012) Recombinant protein expression and purification: a comprehensive review of affinity tags and microbial applications. Biotechnol J 7(5):620-634. https://doi.org/10.1002/biot.201100155

Zasloff M (2002) Antimicrobial peptides of multicellular organisms. Nature 415:389. https://doi.org/10.1038/415389a

Zhang C, He XL, Gu YP, Zhou HY, Cao J, Gao Q (2014) Recombinant scorpine produced using SUMO fusion partner in Escherichia coli has the activities against clinically isolated bacteria and inhibits the Plasmodium falciparum parasitemia in vitro. PLoS One 9(7) https://doi.org/10.1371/journal.pone.0103456

Zhang LC, Li XD, Wei DD, Wang J, Shan AS, Li ZY (2015a) Expression of plectasin in Bacillus subtilis using SUMO technology by a maltose-inducible vector. J Ind Microbiol Biotechnol 42(10):1369-1376. https://doi.org/10.1007/s10295-015-1673-y

Zhang Y, Teng D, Wang X, Mao R, Cao X, Hu X, Zong L, Wang J (2015b) In vitro and in vivo characterization of a new recombinant antimicrobial peptide, MP1102, against methicillin-resistant Staphylococcus aureus. Appl Microbiol Biotechnol 99(15):6255-6266. https://doi.org/10.1007/s00253-015-6394-7

Zhao C-X, Dwyer MD, Yu AL, Wu Y, Fang S, Middelberg APJ (2015) A simple and low-cost platform technology for producing pexiganan antimicrobial peptide in E. coli. Biotechnol Bioeng 112(5):957-964. https://doi.org/10.1002/bit.25505

Zydney AL (2016) Continuous downstream processing for high value biological products: a review. Biotechnol Bioeng 113(3):465-475. https://doi.org/10.1002/bit.25695 


\section{Figure captions}

Figure 1 Overview of the design consideration for the rational production of recombinant antimicrobial peptides (AMPs)

Figure 2 Design of fusion proteins for the recombinant production of antimicrobial peptides (AMPs). Different elements required for solubility enhancer, affinity purification and tag removal are depicted: $A=$ fusion tag $1, \mathrm{~B}=$ fusion tag $2, \mathrm{C}=$ cleavage site, $\mathrm{D}=\mathrm{AMP}, *=$ spacer

Figure 3 Expression screening in E. coli. (A) The plasmid library of E. coli. Yield of fusion protein containing: (B) IMPI, (C) BR021, and (D) AFP antimicrobial peptides resulted from combinatorial plasmid library (A). Rosetta-gami 2 = Rosetta-gami 2 (DE3)pLysS, Origami = Origami 2, SHuffle = SHuffle T7 Express lysY, BL21 = BL21(DE3), C41 = OverExpress C41(DE3)pLysS, C43 = OverExpress C43 (DE3) pLysS. Reproduced with permission (Schreiber et al. 2017)

Figure 4 Fermentation profile of E. coli in defined media with batch (top) and fed-batch (bottom) modes in 0.5 Lfermenter. $\boldsymbol{\boldsymbol { a }}=$ dissolved oxygen (\%), $\boldsymbol{\Delta}$ = glucose concentration $(\mathrm{g} / \mathrm{L}), \boldsymbol{\nabla}=$ acetate concentration $(\mathrm{g} / \mathrm{L}), \bullet$ $=\operatorname{biomass}(\mathrm{g} / \mathrm{L}), \mathrm{I}=$ pre-induction, II-V = after induction with isopropyl $\beta$-D-1-thiogalactopyranoside (IPTG), III = first glucose feed, IV = second glucose feed, $\mathrm{V}=$ third glucose feed. The fermentation profiles were reproduced with permission (Sousa et al. 2016) 


\section{Table}

Table 1. Recent production of fusion proteins containing antimicrobial peptides (AMPs) in shake flasks, and their expression and purification yields.

\begin{tabular}{|c|c|c|c|c|c|c|}
\hline AMPs & $\begin{array}{c}M_{\mathrm{w}} \\
(\mathrm{kDa})\end{array}$ & Fusion tags & Host strain & $\begin{array}{l}\text { Protein } \\
\text { yield } \\
(\mathrm{mg} / \mathrm{L})\end{array}$ & $\begin{array}{l}\text { AMP } \\
\text { yield } \\
(\mathrm{mg} / \mathrm{L})\end{array}$ & Ref \\
\hline Cathelicidin-BF & 3.6 & (His) 6 -SUMO & B. subtilis WB800N & 22.0 & 3.0 & (Luan et al. 2014) \\
\hline $\begin{array}{l}\text { Cecropin A- } \\
\text { LL37 }\end{array}$ & 2.9 & (His) ${ }_{6}-\mathrm{SUMO}$ & E. coli BL21(DE3) & 89.1 & 17.5 & (Wei et al. 2018) \\
\hline LsGRP1 $^{\mathrm{C}}$ & $6-16$ & (His) ${ }_{6}-\mathrm{SUMO}$ & E. coli C41(DE3) & 12.0 & 2.4 & (Lin et al. 2017) \\
\hline Plectasin & 4.4 & (His) 6 -SUMO & B. subtilis WB800N & 41.0 & 5.5 & (Zhang et al. 2015a) \\
\hline Plectasin & 4.4 & (His) ${ }_{6}-\mathrm{SUMO}$ & $\begin{array}{l}\text { E. coli Origami } \\
\text { (DE3) }\end{array}$ & 135.9 & 35.8 & (Chen et al. 2015) \\
\hline Scolopin I & 2.6 & (His) ${ }_{6}-\mathrm{SUMO}$ & E. coli BL21(DE3) & 95.0 & 16.0 & (Hou et al. 2013) \\
\hline Scorpine & 8.0 & (His) 6 -SUMO & E. coli BL21(DE3) & N/A & N/A & (Zhang et al. 2014) \\
\hline Sonorensin & 6.3 & $\begin{array}{l}\text { (His) })_{6}-\text { SUMO- } \\
\mathrm{D} \uparrow \mathbf{P}\end{array}$ & E. coli Rosetta 2 & N/A & N/A & (Chopra et al. 2014) \\
\hline Fowlicidin-2* & 3.8 & Trx-M $\uparrow$ & E. coli BL21(DE3) & 98.0 & 6.5 & (Feng et al. 2015) \\
\hline G13 & 2.3 & Trx-(His) ${ }_{6}-\mathrm{D} \uparrow \mathbf{P}$ & E. coli BL21(DE3) & N/A & 2.95 & (Che et al. 2016) \\
\hline Hepcidins & 4.6 & $\begin{array}{l}\text { Trx-(His) } 6^{-} \\
\text {DDDD } \uparrow \mathbf{K}\end{array}$ & E. coli BL21(DE3) & 6.38 & 0.8 & (Tao et al. 2014) \\
\hline LL-37 & 4.5 & $\begin{array}{l}\text { Trx-(His)8- } \\
\text { SUMO-LL37 }\end{array}$ & E. coli Rosetta & 37.8 & 2.4 & (Li 2013b) \\
\hline OG2 & 2.5 & $\begin{array}{l}\text { Trx-(His) } 6^{-} \\
\text {ENLYFQ } \uparrow \mathbf{G}\end{array}$ & E. coli BL21(DE3) & 50.0 & 6.0 & (Xie et al. 2013) \\
\hline Plantaricin & 7.7 & $\begin{array}{l}\text { Trx-(His) } 6^{-} \\
\text {DDDD } \uparrow \mathbf{K}\end{array}$ & E. coli BL21(DE3) & $\begin{array}{c}100- \\
110 \\
\end{array}$ & $9-11$ & (Meng et al. 2016b) \\
\hline Plectasin & 4.4 & $\begin{array}{l}\text { Trx-(His) } 6^{-} \\
\operatorname{DDDD} \mathbf{K}^{-}\end{array}$ & $\begin{array}{l}\text { E. coli Origami } \\
\text { (DE3) }\end{array}$ & 173.2 & 35.6 & (Chen et al. 2015) \\
\hline Ranalexin & 2.1 & $\begin{array}{l}\text { TrX-(His) }{ }_{6}^{-} \\
\text {IEGR } \uparrow\end{array}$ & E. coli BL21(DE3) & 35.1 & 1.0 & $\begin{array}{l}\text { (Abou Aleinein et al. } \\
\text { 2013) }\end{array}$ \\
\hline Scygonadin & 11.3 & $\begin{array}{l}\text { TrX-(His) } 6^{-} \\
\text {ENLYFQ } \uparrow \mathbf{G}\end{array}$ & E. coli BL21(DE3) & 93.3 & 32.7 & (Li 2013b) \\
\hline Snakin-2 & 7.1 & $\begin{array}{l}\text { TrX-(His) }{ }_{6}^{-} \\
\text {ENLYFQ } \uparrow \mathbf{G}\end{array}$ & E. coli BL21(DE3) & 3.0 & 1.0 & (Herbel et al. 2015) \\
\hline Tachyplesin I* & 2.3 & (His) ${ }_{8}-\operatorname{Trx}-\mathrm{M} \uparrow$ & E. coli BL21(DE3) & 50.0 & 17.0 & $\begin{array}{l}\text { (Panteleev and } \\
\text { Ovchinnikova 2017) }\end{array}$ \\
\hline Pexiganan & 2.5 & DAMP4-D $\uparrow \mathbf{P S}$ & E. coli BL21(DE3) & 30.0 & 2.0 & $\begin{array}{l}\text { (Sun et al. 2018a; Zhao } \\
\text { et al. 2015) }\end{array}$ \\
\hline Pexiganan & 2.5 & $\begin{array}{l}\text { DAMP4- } \\
\text { spacer }^{(2)}{ }_{-} \\
\text {LVPR } \uparrow \mathbf{G S} \\
\end{array}$ & E. coli BL21(DE3) & N/A & N/A & (Sun et al. 2018b) \\
\hline Crotamine & 5.0 & $\begin{array}{l}\text { (His) }{ }_{6}-\mathrm{MBP}- \\
\text { ENLYFQ } \uparrow \mathrm{G}\end{array}$ & E. coli BL21(DE3) & 63 & 0.9 & (Vu et al. 2014) \\
\hline ORBK & 1.8 & $\begin{array}{l}\text { (His) }{ }_{6}-\mathrm{MBP}- \\
\text { ENLYFQ } \uparrow \mathrm{G}\end{array}$ & E. coli BL21(DE3) & N/A & 3.0 & (Li et al. 2014) \\
\hline Palustrin-2CE & 3.3 & GST-DDDD $\uparrow \mathbf{K}$ & E. coli BL21(DE3) & N/A & N/A & (Sun et al. 2012) \\
\hline Dermaseptin S4 & 3.0 & GST-LVPR $\uparrow \mathbf{G S}$ & E. coli BL21(DE3) & 20.0 & 0.6 & (Song et al. 2014) \\
\hline Pa-MAP 2 & 2.5 & ELP-intein & E. coli BL21(DE3) & N/A & N/A & (Sousa et al. 2016) \\
\hline
\end{tabular}

Note:

*the fusion protein was expressed as an inclusion body.

(1) Fusion tag: GST = glutathione S-transferase, ELP = elastin-like polypeptide, $(\mathrm{His})_{\mathrm{n}}=\mathrm{n} \times$ histidine, $\mathrm{MBP}=$ maltosebinding protein, $\mathrm{SUMO}=$ small ubiquitin-like modifier, Trx $=$ thioredoxin.

(2) Cleavage site: $\mathrm{M} \uparrow=\mathrm{CNBr}, \mathrm{D} \uparrow \mathbf{P}=$ acid, $\mathrm{DDDD} \uparrow \mathbf{K}=$ enterokinase, $\mathrm{ENLYFQ} \uparrow \mathbf{G}=$ tobacco etch virus protease, $\mathrm{IEGR} \uparrow$ $=$ factor Xa protease, $\mathrm{LVPR} \uparrow \mathbf{G S}=$ thrombin. Intein is self-cleavable. $\uparrow$ indicates site-specific amino acid sequence for excision; residues in bold remain with the targeted protein following endoprotease cleavage.

(3) Spacer $=\mathrm{P}\left(\mathrm{G}_{4} \mathrm{~S}\right)_{2}$. 
Figure 1

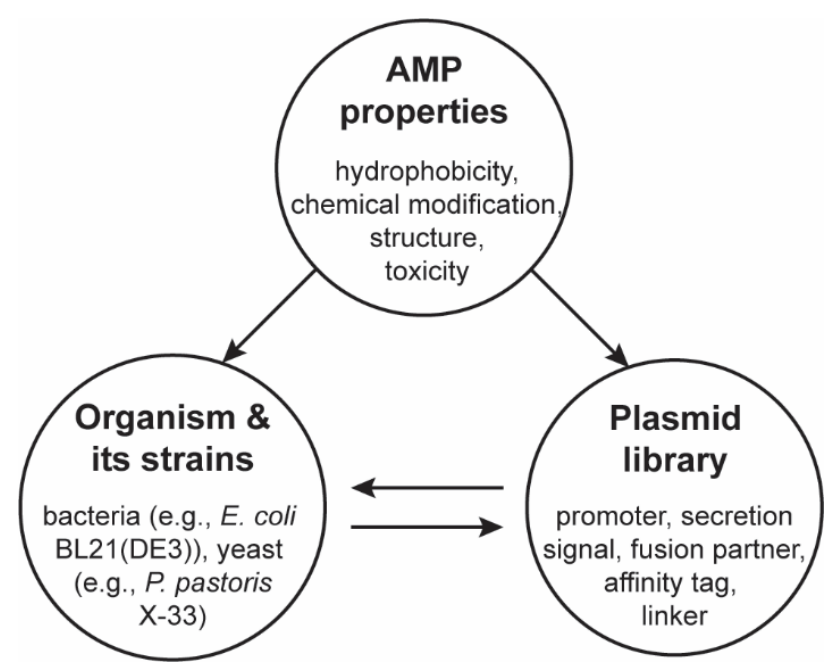


Figure 2

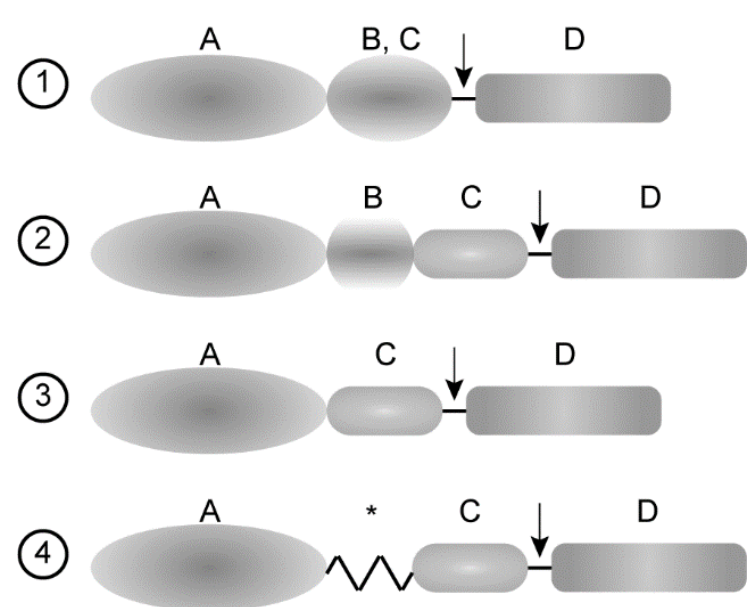


Figure 3
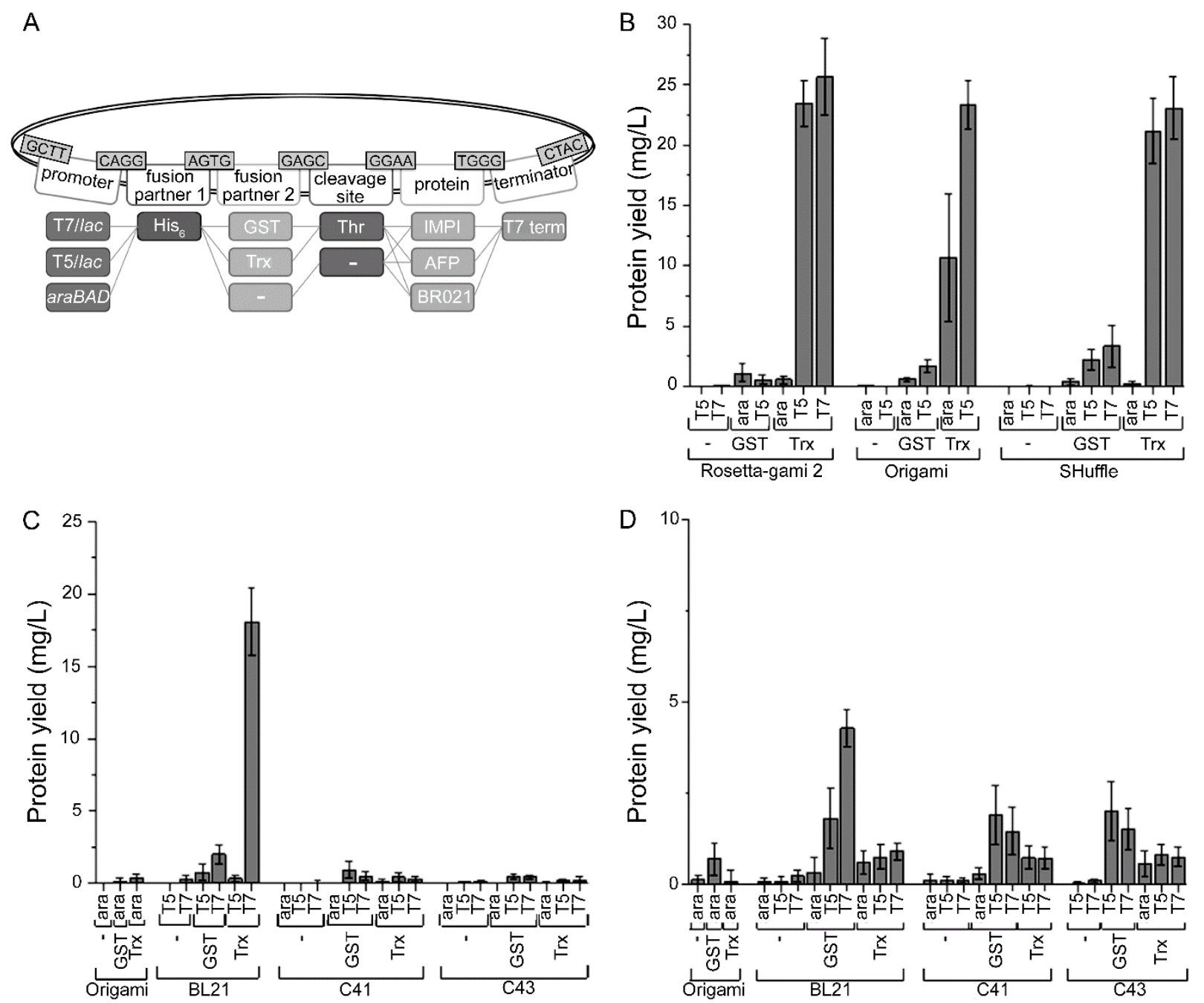
Figure 4
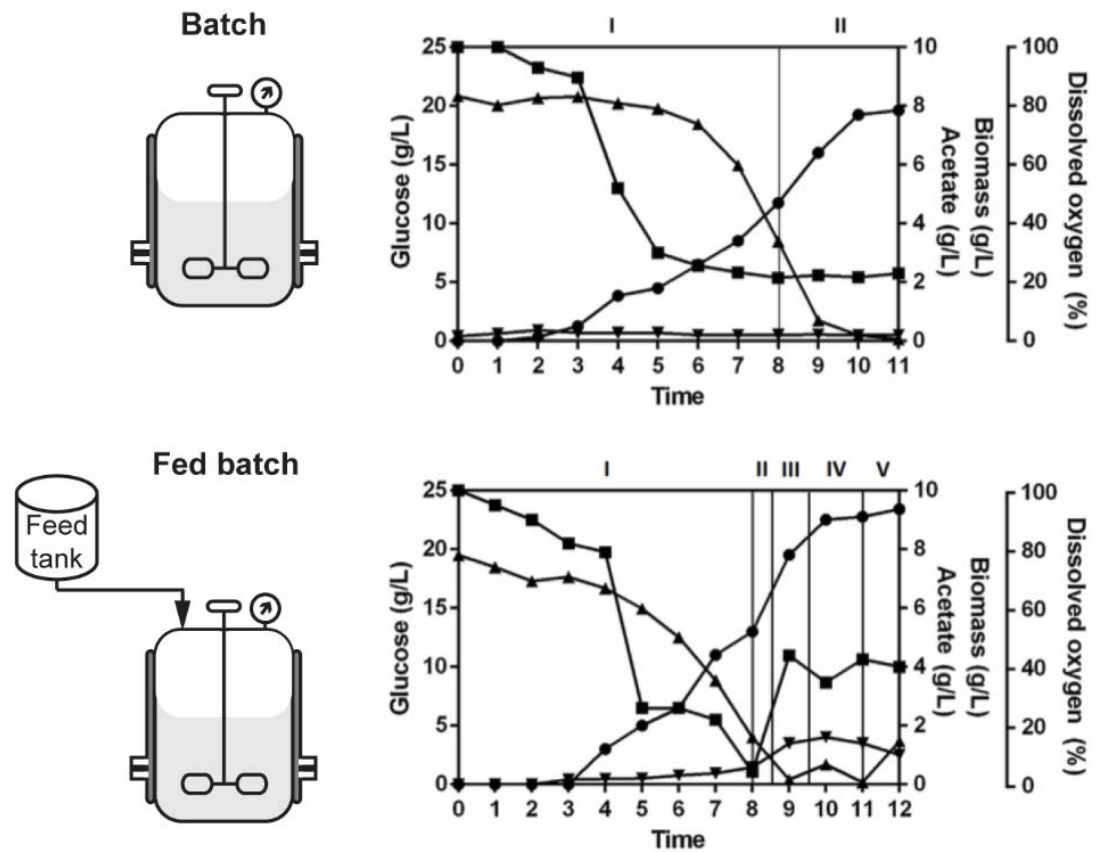